DOI: https://doi.org/10.24297/ijrem.v1i.9128

\title{
Proposal Of a Hypothetical Learning Trajectory Line for The Assimilation of The Concept Of Height Of A Triangle By Using GeoGebra
}

\author{
Armando Morales Carballo, Angie Damián Mojica², Jessica Maldonado Morales ${ }^{3}$ \\ ${ }^{1}$ Epistemología y Didáctica de la Matemática, Facultad de Matemáticas, Universidad Autónoma de Guerrero, \\ México \\ 2 Facultad de Matemáticas, Universidad Autónoma de Guerrero, México \\ ${ }^{3}$ Facultad de Matemáticas, Universidad Autónoma de Guerrero, México \\ armandomorales@uagro.mx, adamian@uagro.mx,morales140192@gmail.com
}

\begin{abstract}
A hypothetical learning trajectory line is described for the assimilation and fixation of the concept of height of a triangle for its treatment in pre-university. The theoretical and methodological basis is based on the processes of assimilation, learning trajectories, problem solving and the use of GeoGebra software. This work provides a didactic proposal aimed at the teacher, different from the classic presentation for the treatment of the concept of height, highlighting that the use of the software favors the processes of assimilation of this concept through the dynamic-visual activity, use of the geometric and numerical resource that this technological tool makes possible.
\end{abstract}

Keywords: Height of triangle, trajectory, learning, assimilation.

\section{Introduction}

The concept of height is a fundamental concept in the study of plane geometry, in particular, its use is indispensable in the treatment of the concept of area and properties of the triangle. Some historical and epistemological data highlight that this concept is developed at the same time as the classical formula for determining the area of a triangle is constructed, since prior to the generalization of this formula and its application to any triangle, the area of a right triangle was first defined, the justification for this consisted of forming a rectangle and then taking half the product of the unequal sides of the rectangle (product of the legs of the right triangle); it is here where the concept of the height of a triangle appears implicitly.

To generalise the definition of the area of any triangle, the concept of height is first defined "as the perpendicular to the opposite side of a triangle from a vertex", the length of the height is the length of the segment that goes from the foot of the height (point of intersection of the height with its perpendicular side) to the opposite vertex.

Research in the field of mathematics education has highlighted that this concept begins to be worked on at primary level and has documented that, from an early age, errors and difficulties are identified in its treatment and in the learning, activities aimed at students.

Recently, in an exploratory study on errors and difficulties of the triangle's notable lines and points in preuniversity students (Morales and Damián, 2021) identified difficulties associated with mathematical thinking processes in pre-university students: examples of notable lines (height, median, bisector and bisector) emerged in particular cases of triangles, the non-standard representations of the figures are a factor of difficulty for students, which led them to make errors in the representation and construction. The difficulties associated with the teaching processes for learning; were manifested in each answer to the questions of the exploration design, since the equivocal or partially correct answers evidenced the need to contribute in the planning tools to improve the learning of the mathematical content at stake.

In this regard, Jaime and Gutiérrez (2016) in their model of explanation on the learning of geometric concepts in elementary school, emphasize that students generally receive two types of information, verbal and graphic, transmitted by the teacher, the textbook, among others. As a result of the review of primary school textbooks, the researchers found that most of them do not define the concept of height either for quadrilaterals or for triangles, but limit themselves to drawing the heights of polygons (always in the prototypical vertical position) 
when they present their formulas for calculating areas, although in some cases the height is not even drawn. The researchers emphasize that trying to make elementary school students learn a geometric concept implicitly, based only on some cases (specific drawings) is a didactic error since it tends to generate erroneous conceptual images in the students. In addition, they identified that of the lines and notable points of the triangle, only the height is implemented from the basic level indicated, and this is exemplified in triangles represented in the standard form (triangles whose base is horizontal).

Samper et al., (2014) report a study directed to pre-university students, in which their objective was to study the conceptualization processes of the concept of triangle height. In the exploration through a questionnaire they implemented, it was identified that in the question ils the height of a triangle a segment? the influence of conceptual images about the concept prevails, since they represent a segment that visually satisfies the invariants of the definition; a minority does not make any report. The researchers emphasize that these images harbor conceptual errors that are difficult to remove, since the term is more general and appropriate. In relation to question number 2 , is the foot of the height a point between two vertices of a triangle? It was identified that more than 50 percent of the experimental population mentioned yes, only a small number stated yes; whether it is an acute or obtuse triangle. It is observed that in most of the students assume the definition of height as "it is the perpendicular line drawn from a vertex to the opposite side" (Jaime and Gutiérrez, 2016). This conception causes conceptual errors in some students, assuming that there is no height or that it is not perpendicular to the base. In relation to question 3, which deals with the representation of a triangle in a nonstandard position, in which it is asked to explain about the height (not posed as height). It was identified that a population greater than $50 \%$ presented a personal space of complete examples, while a reduced group proposed answers analogous to those given in question 2.

In relation to question 4, where it was asked to demonstrate that "the height relative to the base of an isosceles triangle is median", no production was identified in the students, the authors attribute this to the fact that there were no conditions to establish a relationship between the personal definition, the definition of the concept, the conceptual image and the figurative representation of the height of a triangle in a demonstration context. In this regard, Gutiérrez \& Chapa (2012) reported that in most cases the students' activity is based on the use of their conceptual images, since there is a high number of them whose definition is inactive (they know how to recite it, but do not use it when solving problems) or does not exist (they forgot it or never learned the definition). As an example, they showed cases of students making the same types of errors about the concept of height of a triangle. The top row of Figure 1 shows the case of a student whose conception of height of a triangle is incorrect, because in triangles whose height is not interior he draws the median instead of the height. The bottom row of the same figure shows the case of another student whose conception of height is correct but incomplete, since in the obtuse triangles he draws a height that does not correspond to the requested height. The researchers agree that the various mental images of the concept of height are associated with figurative images of physical objects, mental visualization of formulas or diagrams, images of patterns, kinetic images and dynamic images (which are mental images in which objects or some of their elements move). 


\section{Figure 1}

Representations of height and median in triangles.

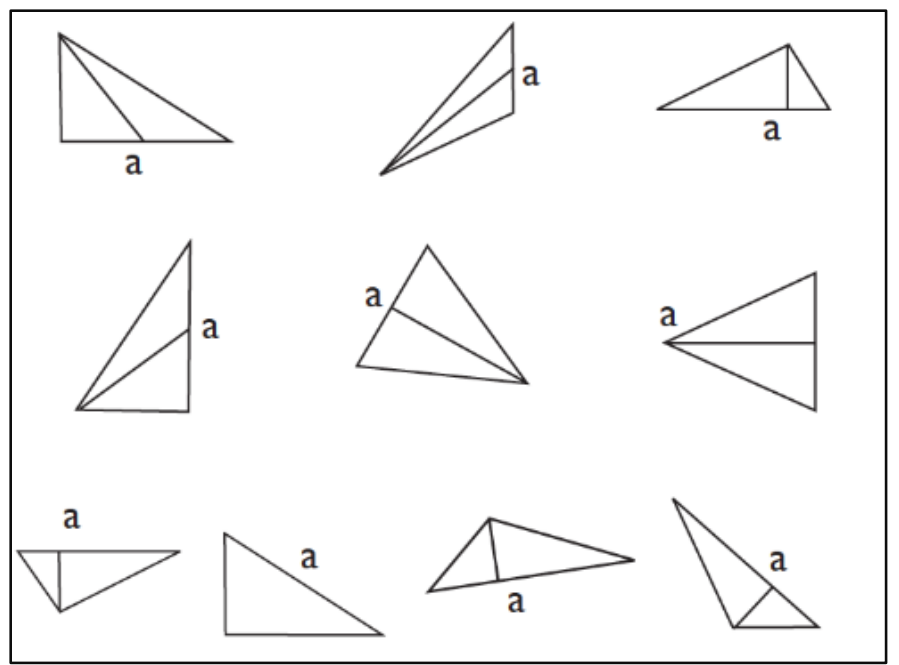

Note: Representation of the height in triangles in non-standard position. Source: Taken from Gutiérrez \& Chapa, 2012, p. 67.

It should be noted that this type of conceptual images were also corroborated in a group of future elementary school teachers (Blanco, 2001) and in the work carried out by Azcárate (1997).

The concept of height of a triangle in pre-university curricula. The concept of height of a triangle is part of the content of notable points and lines of the triangle and is proposed in the study plans and programs of geometry at the primary, secondary, pre-university and university levels in the area of mathematics, at least in Mexico. At the pre-university level, the content is suggested in the study plans and programs of the different higher secondary education systems (Centro de Bachillerato Tecnológico Industrial y de Servicios (CBTis), Colegio de Bachilleres (COBACH) and Escuelas Preparatorias de la Universidad Autónoma de Guerrero (UAGro), however, the absence of a proposal that responds to the conception of a methodological approach for its treatment has been identified in these contents.

Considering the previous references and the justification of the object of research, the objective of this work is the elaboration of a hypothetical line of learning trajectory for the assimilation and fixation of the concept of height of a triangle, in the teaching of geometry in pre-university. The activities framed in the proposal areformulated as problems, and GeoGebra software was used as a heuristic tool for the resolution processes.

\section{Materials and Methods}

Process of assimilation of concepts. Concepts are part of the mathematical structure and play a fundamental role in the development of mathematical knowledge and in the explanation of objective reality (Ballester, 1992). A large part of the difficulties in the comprehension of mathematical content documented in the research lies in the absence of the treatment of concepts. In this work it is assumed that the comprehension of concepts requires two fundamental activities: formation and assimilation (fixation); the treatment of each of these components influences comprehension. Under this perspective, the present research seeks to contribute resources to influence the assimilation of concepts, in particular, the height of a triangle.

The research works of Morales et al., (2014) and Arteaga et al., (2009) are consistent in relation to the concept of assimilation of a mathematical content and conceive it as the exercises, deepening, systematization and applications of the concept. In particular, Morales et al. (2014) suggest that in order to achieve the process of assimilation of a concept, the following stages must be fulfilled: Approximation to the concept. In this stage, the concept is recognized at an intuitive level in its different representations; it is necessary to operate with it in order to differentiate it from other concepts about mathematical objects. Formalization of the concept. The formalization of the concept covers the bases of the previous phase, and is essentially aimed at favoring the 
process of formation and definition of the concept, therefore, methodologically, the following are considered: approximation, definition and analysis as fundamental stages of this process (of the didactic proposal), and within it, a hypothetical learning path of the concept of height of a triangle is developed. Identification of the concept. In this phase some ways of identification of the concept are proposed (in the geometric, numerical, algebraic-analytical register). Application of the concept. Two types of problems that favor assimilation through application are analyzed, which strengthens the conceptual part as well as the application to problem solving.

In each of the stages of the assimilation process, heuristic procedures are a fundamental tool since they constitute mental search resources that allow guiding and contributing elements in the processes of understanding and determining the concept on the basis of problem solving (Torres, 2013). According to the author, heuristic procedures are classified into principles, rules and strategies which interact during the processes of searching, elaboration and application of the solution path. Thus, heuristic principles constitute suggestions for directly finding the main solution idea of resolution; they also make it possible to determine the means and the solution path. The strategy presented here potentiates the dynamic-visual through the use of software, considered as a resource for the identification of invariant properties of the concept and the identification of ways of resolution.

The heuristic rules act as general impulses within the searching process and help to find the means to solve the problem. In this regard Müller (as cited in Torres, 2013) classifies heuristic rules into general and special. The general rules are: if you have to prove equality of lengths or amplitudes, try to find equal triangles containing those homologous segments or angles. If the searched figure does not lead you immediately to the desired result, try to obtain, by means of auxiliary lines, figures that are easy to construct. Some special rules are: The method of geometric transformations which lies in constructing a figure that partially meets the required conditions and then obtaining the figure of interest by means of a geometric transformation.

Hypothetical learning trajectories (HLT). Simón \& Tzur (2004) identify the main characteristics of the notion of hypothetical learning trajectory as follows: a hypothetical learning trajectory $(H L T)$ consists of the objectives for student learning, the mathematical tasks to be used to promote learning, and the hypotheses about the learning process. In this direction, researchers such as (León et al., 2014) agree that THAs refer to the teacher's predictions about the path along which learning can be mobilized, are hypothetical due to the fact that the actual trajectories of students' learning depend on the conditions of existence of each individual and on the fact that individuals' learning has certain regularities. In addition, they establish that the THA provide the researcher with rational criteria for deciding the design to be considered and the conjectures of how to make learning evolve. The tasks are selected based on hypotheses about the learning process; the hypotheses about this learning process are based on the proposed tasks.

In this work, it is conceived that in the elaboration and implementation of a hypothetical learning trajectory, the teacher or the teacher-researcher can essentially intervene. From this point of view, the teacher-researcher is conceived as the one who in his teaching practice identifies problems, both in teaching and learning of mathematical contents; essentially at the level in which he is involved, this situation forces him to inquire about the reasons for these problems, in order to then project a hypothetical learning trajectory; first from the theoretical level and then for its implementation.

The elaboration of the hypothetical learning trajectory must contemplate all the elements that support it as a construct: understanding of the current knowledge of the students who will receive the instruction, description of fundamental aspects on assimilation and fixation, the selection of tasks, and the mathematical and methodological preparation of the teacher for possible intervention, in case it is required to modify some aspect of the THA.

With the implementation of the Hypothetical Learning Trajectory, the student's cognitive development is affected (Gómez \& Lupiañez, 2007). In this regard, the researchers state that it is necessary to carry out an initial analysis of it, so that the teacher can describe his hypotheses about how students can progress in the construction of their knowledge about the mathematical structure, when they face tasks about the mathematical object of interest. 
GeoGebra software. It is part of the technological tools, it is a software that favors the dynamic-visual activity and that makes possible the treatment of mathematical contents in the different educational levels. Through the dynamic-visual activity in the treatment of a mathematical object, processes of rediscovery of numerical, geometric and algebraic behaviors are favored. The construction processes and geometric transformations that can be performed are an important tool for the treatment of content such as area, situations of area preservation, congruence and similarity of triangles, among others.

The use of GeoGebra as a heuristic tool makes it possible to evolve processes that have generalization through the rediscovery of behavioral patterns. The software alone does not provide the solutions to different situations, this is given as the individual manipulates, tests or carries out pre-elaborated or theoretically valid actions such as rediscovering, formulating conjectures, proposing solution strategies and carrying out the resolution of activities or problems in the approach to the contents. In this direction is that the dynamic-visual representation and the treatment of this, which favors the software, becomes a methodological resource for the teaching and learning of geometry, by contributing to enhance the dynamic-visual, understanding, teaching and learning. With the aforementioned, in this work we will assume the GeoGebra software as a heuristic resource mediator of the teaching and learning processes, the dynamic-visual activity that favors as the association of images-ideas contributes in the internalization of the processes of abstraction on the mathematical contents to be treated.

Problem solving. Without going into a detailed analysis of the problem concept, this paper assumes that in a problem: there is an initial situation and a final situation, the way to go from the initial situation to the final situation is unknown, there is a person who wants to solve this situation, and he/she has the necessary elements for the resolution.

\section{Hypothetical learning trajectory of the concept of height of a triangle.}

The proposal considers seven activities accompanied by actions that are carried out with the support of GeoGebra software. The activities are serial and graded, and their elaboration is based on the principles of assimilation. The validation of the activities was carried out at the theoretical level, that is, through the criteria of experts, in that sense the proposal is of a theoretical-didactic type.

As part of the process of assimilation and fixation of the concept, it is considered fundamental to carry out operations with these concepts; these activities influence the identification and analysis of the invariant characteristics of the concept, in this case the height of a triangle. The proposed activities are related to isometric transformations: translation, rotation and reflection of geometric objects, given the nature of this work we chose to exemplify the transformations in segments and triangles; representation of families of triangles in nonstandard positions; review of formulas to determine the measurement of triangle areas; identification of the concept of height and its representation.

\section{Results and Discussion}

Activity 1. Motivational action. In this phase it is intended to influence the teacher or the student to reflect on their notions in the calculation of areas of figures that are not represented in the standard form. For this purpose, two activities are planned. The first one has the objective that the teacher identifies the importance of working with the spatial as an important element in the operational process of the concepts, as is the case of area. Therefore, here the need to know the measurement of the base and the height of the figures is identified, assuming that in all cases the bases are horizontal. The second activity has the purpose of having the teacher look for other means that favor the representation of plane figures and with it, the conceptual operational part. In the case of the students, this activity can contribute to reduce the conceptual images that hinder the understanding of the concepts and their definition.

Action 1. Describe a procedure to determine the measure of the area of the triangle $A B C$, and of the quadrilaterals DEFG and HIJK. 


\section{Figure 2}

Representation of plane figures in non-standard position.

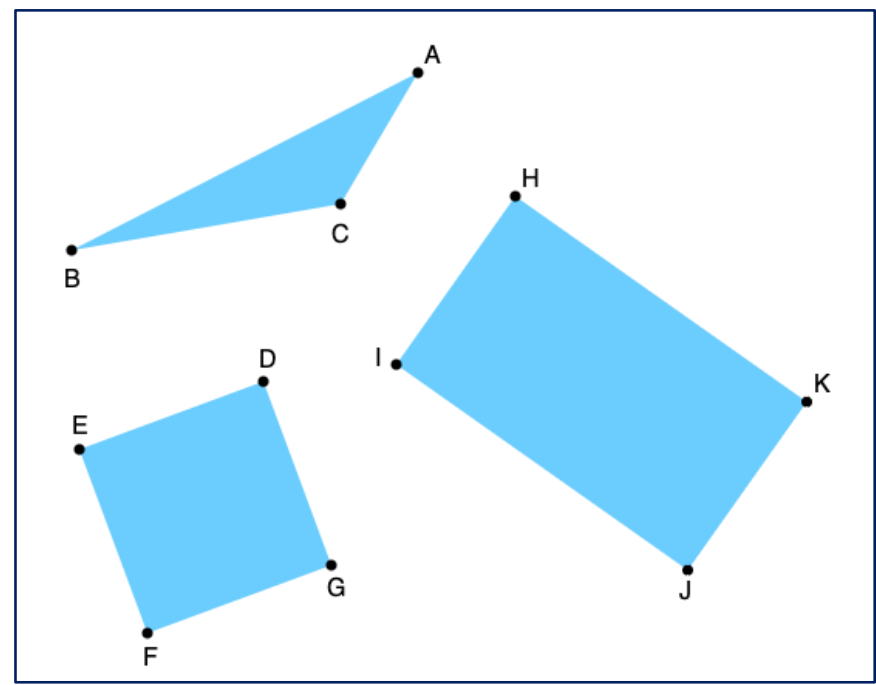

Note: Familiarization with the non-standard representation of geometric figures. Source: Own elaboration.

Describe some strategies that favor the transformation of the figures given above, Figure 2, to the figures that make up Figure 3.

\section{Figure 3}

Representation of plane figures in the standard position.

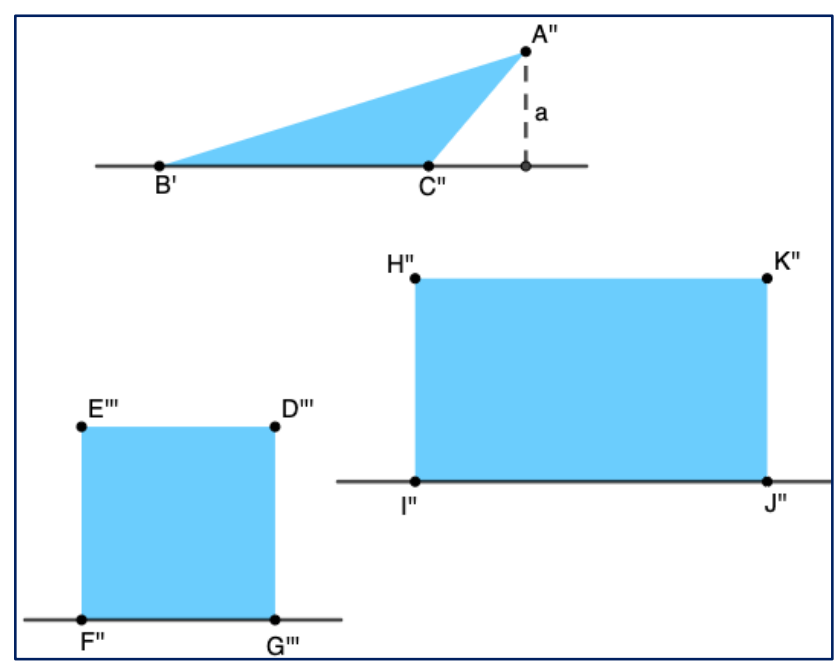

Note: Visualization of the effects of the isometric transformations that favor the standard position of the figures. Source: Own elaboration. Source: Own elaboration.

Activity 2. With the instructions described in Table 1 and executed with GeoGebra, the translation, rotation and reflection transformations are carried out. Here the aim is to familiarize the teacher with isometric transformations and with the use of the software. 


\section{Table 1}

Description and representations of the isometric transformations
Action
Description
Representation

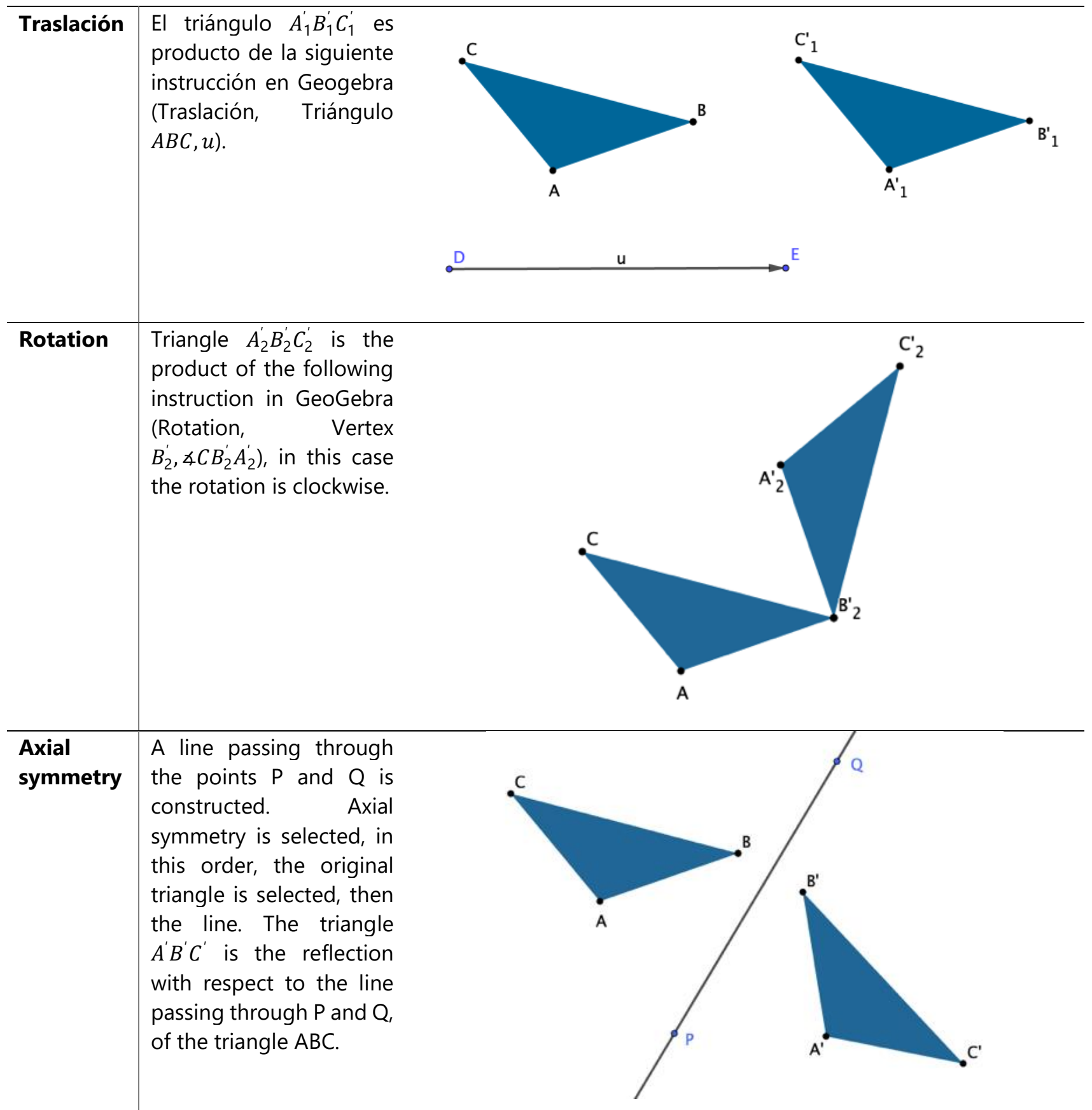

Note: This activity is intended to show that a plane figure placed in any position has invariant properties when an isometric transformation is applied to it.

Activity 3. List and describe the formulas known to determine the measure of the area of a triangle. This activity is fundamental, since it is agreed that the concept of height and its generalization is necessary to deduce one of the classic formulas currently in use, which is used to determine the area of a triangle "half the product of the base times the height". Therefore, it is not out of place that in the students' or the teacher's conception, the first approaches for the calculation of the area should appear, considering that half the product of the legs allows determining the area of a right triangle or the scheme to make the justification, that is, to complete the rectangle 
and half the area of it, will be the area of the triangle and, finally, to seek in the students or in the teacher himself that processes of generalization emerge, this way will help to identify that the height is fundamental to make possible the determination of the measurement of the area.

Another of the formulas that can be proposed is the one given by "half the product of two sides of a triangle, multiplied by the sine of the angle formed by these sides", a particular case that makes the concept of height patent is that it is a right triangle, in such a case, the sides considered are the legs and the angle formed by them, will be a right angle. From this we conclude that one of the legs (or any of them can be the height). A third approach is the one associated with Pick's formula, this counting method together with translation and rotation can favor elements of understanding, by identifying that in the passage from Pick's formula to the classical formula, the concept of height is fundamental (Morales, et al., 2019; Morales et al., 2020).

Activity 4. Identification of the height of a triangle and its representation in a set of triangles, some of them have the median drawn. In this activity we try to identify the heights of a triangle, when this geometric object is represented in a non-standard position. Once the identification and representations have been made by means of isometric transformations, it is required to take these representations to the standard position and verify that the heights are maintained in length and in complying with the condition of perpendicularity with respect to the base or its prolongation, this will help to establish in which particular cases the height and median coincide.

Activity 5. Taking as reference Figure 4, it is asked to determine the lengths of the heights of the triangles $A B C$, $A D C$ and $A E C$ from vertex $A$ to the opposite sides $B C$ and $C D$, from vertex $C$ to the opposite side $A E$, considering also that $H B=H D=H D=G C=A F=A F=1$. With this activity it is intended that the teacher or the student through the dynamic-visual resource made possible by the software conjecture the measure of the height, and subsequently justify mathematically this conjecture, in addition, that this exercise is designed to overcome the obstacle of considering the height, always as a side of the triangle.

\section{Figure 4}

Representations of triangles in a square of side 4 units.

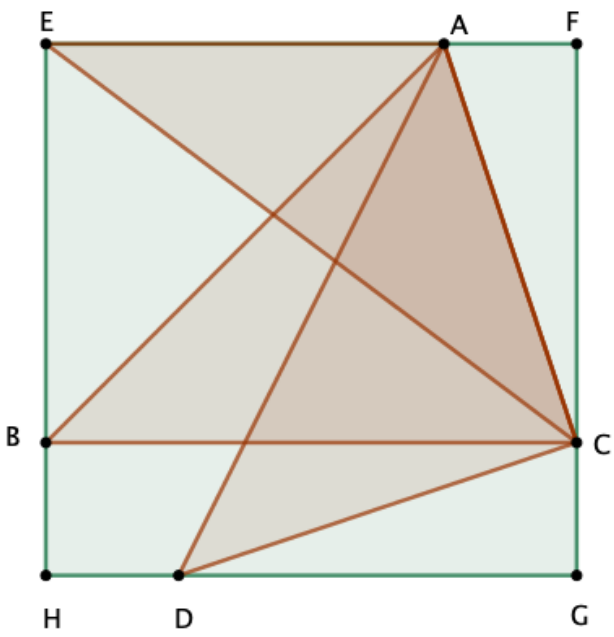

Note: By means of geometric and algebraic resources, the height of the triangles inscribed in a a square of side 4 units. Source: Own elaboration.

Activity 6. An activity is proposed in which the condition that the height of a triangle fulfills in an equality relation is identified. In Figure 5 a triangle $A B C$ is represented, and point $D$ is located at the foot of the height (perpendicular to the considered base $\mathrm{BC}$ ). By using the following result (deduced by the reiterative application of the Pythagorean Theorem): $A B^{2}-A C^{2}=D B^{2}-D C^{2}$, it can be identified that any point $\mathrm{P}$ that is on the segment representing the height, also satisfies the equality relation $P B^{2}-P C^{2}=A B^{2}-A C^{2}$. This activity is important, since both the teacher and the student have the possibility to prove that any point in the height of a triangle satisfies the same equality relation, this task approaches to conceive the height as a geometric locus (a 
dynamic view) and implicitly strengthens the condition that "the height is perpendicular from the vertex to the opposite side or to the prolongation of it".

\section{Figure 5}

Representation of the height $A D$ of triangle $A B C$ satisfying the relation $A B^{2}-A C^{2}=D B^{2}-D C^{2}$

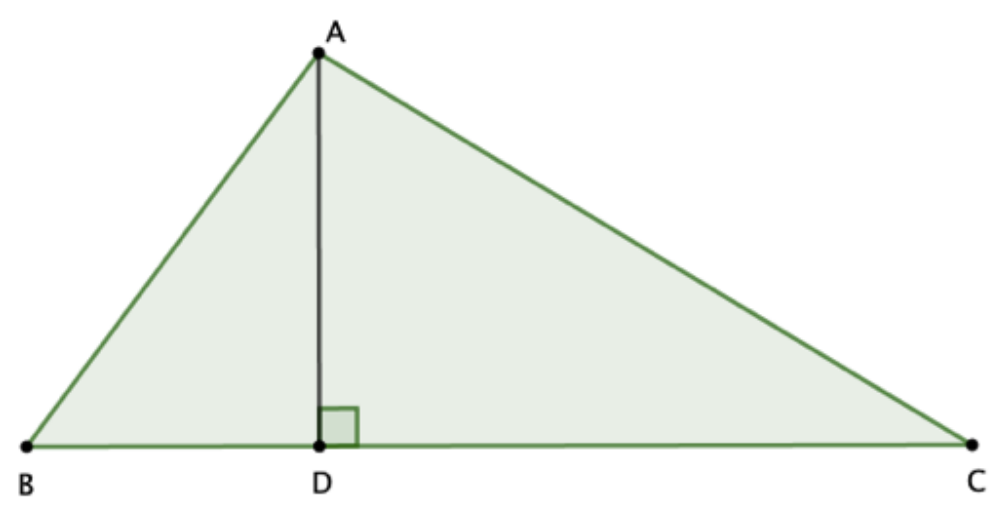

Note: For any point that lies on the height of the triangle, the given relationship always holds. Source: Own elaboration.

Activity 7. In this activity two types of applications of the concept of height to fixation are exemplified by solving problems.

If two triangles have the same height then the ratio between their areas is equal to the ratio of the bases where the height rises.

The most important thing in this type of resolutions is to identify the given information, and the requirement. In second instance, explore particular cases through the use of the software, with this tool the fulfillment of the conditions and requirement of the problem is verified. Subsequently, the generalization is sought, for it is identified that part of the hypothesis or information given as valid is that the two triangles have the same height, thus, if the areas of the given triangles are represented by $(\triangle[A B C])$ and $(\triangle[D E F])$, then their areas are given by $(\triangle[A B C])=(B C \cdot h) / 2$ and $(\triangle[D E F])=(E F \cdot h) / 2$, where the sides $B C$ and $E F$ are the bases and $h$ the height. By forming the ratio of the areas, we obtain that $\frac{\Delta[A B C]}{\Delta[D E F]}=\frac{\frac{B C \cdot h}{2}}{\frac{2}{E F h}}=B C / E F$. We conclude with the justification of the requirement.

If two triangles have an equal base then the ratio of their areas is equal to the ratio between the heights that rise above the equal base, in Figure 6 the situation is represented.

\section{Figure 6}

Representation of two triangles with a common base and different heights.

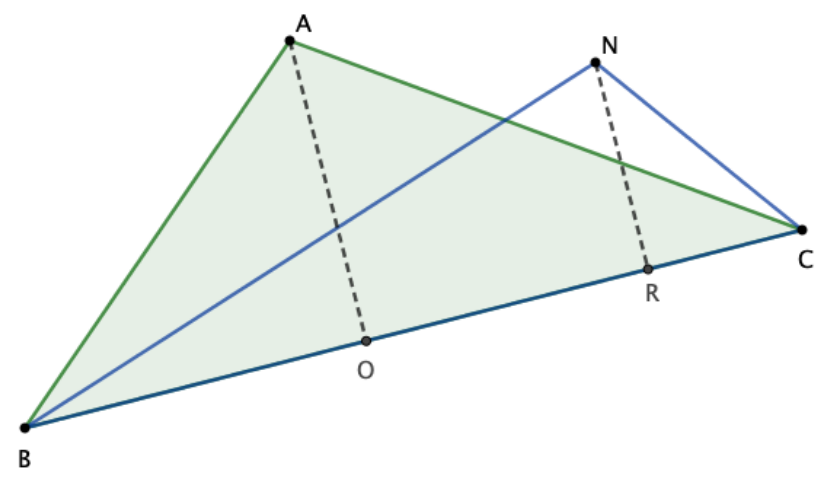


Note: It is about identifying that the common side of the triangles is a condition to make the relationship possible. Source: Own elaboration.

A first approach towards the interpretation and determination of the solution is favored by means of the verification in particular cases. Using GeoGebra, the heights were made to vary while maintaining a common base, as shown in Figure 6. After the process of verifications in particular cases, we proceed to look for generalization, using as a mathematical element the classical formula for measuring the area of a triangle (in the previous activities this possibility was ensured by using isometric transformations). Thus, the areas of triangles with a common base are determined, the ratios of the areas are formed, and it is shown that this ratio is equal to the ratio between the respective heights. Next, activities of fixation and application of the concept of height are proposed, for the independent work of the teacher or the student working under this proposal.

If $\mathrm{b}$ and $\mathrm{c}$ are the legs of a right triangle, $a$ the hypotenuse and $h$ the height above $a$ e $y^{\prime}, x^{\prime}$ the projections of the legs onto the hypotenuse, then the following results are satisfied: i. $h^{2}=x^{\prime} y^{\prime}$, ii. $a h=c b$.

Given a triangle $A B C$ whose vertex coordinates are $A(0,5), B(-3,0)$ and $C(5,0)$.Determine the equation of the height from vertex $A$ to the opposite side.

If a triangle has its vertices in the Cartesian plane. Describe the concepts and properties needed to construct the equation of that height, from any of its vertices to the opposite side or its prolongation.

\section{Conclusions}

The proposal contributes with a hypothetical learning trajectory line of the concept of height of a triangle and the specific activities contribute to the processes of assimilation and fixation of this concept. This elaboration provides to the pre-university teacher a different vision from the classical scheme of presentation and treatment of the lines and notable points of the triangle of the concept of height. On the other hand, the realization of the activities by the students of this level will allow them to give meaning to the mathematical content of the concept promoted in the classroom, the dynamic-visual that favors the GeoGebra software and the isometric transformations carried out in the treatment that has been described; they also contribute to diminish the difficulties of operational, relational, determination, spatial representation, and application type.

The GeoGebra software played the role of heuristic revealer in the development process of each activity, the numerical validation of the situations that were carried out with this technological tool were the ones that made possible the solution paths for the general case.

\section{References}

1. Arteaga, E., Díaz, A., Gracía, F. y Del Sol, J. L. (2009). Alternativas metodológicas para la formación y fijación de conceptos geométricos en la geometría plana. Cuaderns Digitals, 0(60), 1-25.

2. Azcárate, C. (1997). Si el eje de ordenadas es vertical, ¿qué podemos decir de las alturas de un triángulo?, SUMA, 25, 23-30.

3. Ballester, S. (1992). Metodología de la enseñanza de la Matemática. La Habana: Editorial Pueblo y Educación.

4. Blanco, L. J. (2001). Errors in Teaching/Learning the Basic Concepts of Geometry. International for Mathematics Teaching and Learning, 2(2), 1-11.

5. Gómez, P. y Lupiáñez, J. L. (2007). Trayectorias hipotéticas de aprendizaje en la formación inicial de profesores de matemáticas de secundaria. PNA-Revista de Investigación en Didáctica de la Matemática, $1(2), 79-98$.

6. https://doi.org/10.30827/pna.v1i2.6214

7. Gutiérrez, Ángel, \& Jaime, A. (2012). Reflexiones sobre la enseñanza de la geometría en primaria y secundaria. Tecné Episteme y Didaxis: TED, (32), 55-70. 
8. https://doi.org/10.17227/ted.num32-1859

9. Jaime, A. y Gutiérrez, A. (2016). El aprendizaje de conceptos geométricos en la Educación Primaria. En J. Carrillo y otros (Eds.), Didáctica de las matemáticas para maestros de Educación Primaria, (pp. 197-215). Madrid: Paraninfo.

10. León, O. L., Díaz Celis, F., \& Guilombo, M. (2014). Diseños didácticos y trayectorias de aprendizaje de la geometría de estudiantes sordos, en los primeros grados de escolaridad. Revista Latinoamericana De Etnomatemática Perspectivas Socioculturales De La Educación Matemática, 7(2), 9-28. https://www.revista.etnomatematica.org/index.php/RevLatEm/article/view/109

11. Morales-Carballo, A., Marmolejo-Valle, J. E., Ríos-Parra, B. y Damián-Mojica, A. (2019). Propuesta teóricodidáctica para la enseñanza y aprendizaje del concepto del área. Revista Premisa, 21 (81), 5-20.

12. Morales, A., Damián, A. \& Venancio, A. (2020). El software GeoGebra un recurso para la enseñanzaaprendizaje del concepto de área. En L. A. Hernández, G. Kantún, y J. Slisko (Eds.), Tendencias en educación matemática (pp. 152-170). Puebla, M.: Benemérita Universidad Autónoma de Puebla.

13. Morales Carballo, A., \& Damián Mojica, A. (2021). Errores y dificultades acerca de las rectas notables del triángulo. UNIÓN-Revista Iberoamericana de Educación Matemática, 17(61), e005. https://union.fespm.es/index.php/UNION/article/view/254

14. Samper, C., Corredor, O. A. \& Echeverry, A. (2014). Definición de altura de triángulo: ampliando el espacio de ejemplos con el entorno de geometría dinámica. Tecné Episteme y Didaxis: TED, (35), 63-86.

15. https://doi.org/10.17227/01213814.35ted63.86

16. Simon, M. A. \& Tzur, R. (2004). Explicating the Role of Mathematical Task in Conceptual learning: An Elaboration of the Hypothetical Learning Trajectory. Mathematical Thinking and Learning, 6(2), 91-104. https://doi.org/10.1207/s15327833mtl0602 2

17. Torres, P. (2013). La instrucción heurística en la formación de profesores de Matemáticas. En C. Dolores, M.S. García, J. A. Hernández, L. Sosa (Eds.), Matemática Educativa: La formación de profesores, (pp. 205221). Díaz de Santos.

\section{Conflicts of Interest}

The authors have not conflicts of interest to report.

\section{Funding Statement}

The authors completed this research as part of their normal continuing professional development and scholarly activity. 